\title{
An introduction to the special volume on the biology of hypogean fishes
}

\author{
Aldemaro Romero \\ Environmental Studies Program and Department of Biology, Macalester College, 1600 Grand Ave., St. Paul, \\ MN 55105-1899,U.S.A. (e-mail: romero@macalester.edu)
}

\section{Patterns, diversification, and something else}

Hypogean fishes have always been a source of amazement and amusement throughout the history of ichthyology (Romero 2001). Controversies have ranged from evolutionary issues to behavioral adaptations, from taxonomy to ecology. The fundamental reason behind those controversies is that a number of adaptations usually referred to as 'troglomorphisms', especially blindness and depigmentation, have already been found in nearly 90 species that are largely taxonomically unrelated (Romero \& Paulson 2001). Although reduction and/or loss of eyes and pigmentation seem to be common, the degree to which they occur varies and, to make matters more complicated, not all hypogean fishes have those adaptations. In some cases these species/populations freely come in and out of caves; in others, our access to them has been limited to occasional collections from wells. In some cases these species are known from a single specimen; in others they are represented by several populations. Some hypogean habitats in which these fishes are found seem to be very poor in nutrients, while others are supplied with constant and abundant amounts of organic material. In most cases, the fish in question is the only vertebrate found in its habitat, in others, they share their habitat with other hypogean fishes. Many species of non-hypogean fishes show some of the features of cave fishes. That is the case of fishes living in murky waters or the deep-sea; however, no hypogean fish has been found displaying some of the remarkable adaptations of abyssal fishes such as bioluminescence and darkening coloration.

Thus, besides being subject to (in most cases) permanent darkness, there seems to be no common rule to be applied here, or is there?

One of the pursuits of science is finding common patterns in nature; however, that goal has remained elusive for hypogean fish researchers. Some of those researchers have devoted their entire life to the study of a particular species or a particular problem among hypogean fishes; others have only visited this subject in order to test their ideas in a particular field. Studies have ranged from taxonomy to behavior, from morphology to ecology; methodologies have encompassed field studies as well as the application of the latest behavioral and molecular laboratory techniques. No wonder there is a lot of information out there but not too much of a synthesis.

So far the only attempt to provide such a synthesis was Thinès's (1969) book, which was largely a compilation of known facts. Since then, many changes have occurred; not only have a great deal of new species been discovered, but new approaches have been taken that have profoundly influenced how the scientific community looks at this subject. Hence, the idea of this special volume on the biology hypogean fishes.

Here we present 27 articles written by 38 tuthors from nine countries. Some of them tackle very specific issues; others provide a syntheses on specific issues. What follows is a general overview of these articles.

\section{As a matter of introduction}

Romero \& Paulson (2001) provide a general list of hypogean fishes that present well-established troglomorphism. There they summarize information not previously synthesized elsewhere, with special emphasis on those features that could be used for comparative purposes to better understand the biology of these fishes. Thus, in addition to the scientific names and the (not always known) common names for these fishes, the article includes information about the etymology of their scientific name, major synonyms, history, distribution, habitat and ecology, and remarks of troglomorphisms found among these species as well as any other unusual feature described for them. Included in this article are references to two poorlystudied features that may be more common than 
previously thought: structural simplification or loss of both their scales and swim(gas)bladder. Remarks are also made regarding the possible phylogenetic relationships of each species.

Romero's (2001) article on the history of hypogean fish research represents an attempt to give a historical context to past and present efforts to understand the biology of these animals. It contains both qualitative and quantitative information on how research has progressed through times, defining the rather clearcut historical periods which were largely influenced by philosophical concepts and geography. This article tries to explain why if hypogean fishes represent such an interesting model for evolutionary studies, they have yet to become a popular model for research among non-speleological investigators.

Poly (2001) provides not only a study on nontroglobitic fishes for a particular cave in West Virginia, but also synthesizes information about other nontroglobitic species from the rest of the world. This represents a new and healthy trend: students of cave fishes had until recently concentrated almost exclusively on hypogean fishes with troglomorphic features considering non-troglobitic ones as mere 'accidentals' worthy of little more than a footnote. Yet, with the gradual abandonment of typological views and the understanding that these fishes can actually provide clues to understanding hypogean fish evolution (they are sort of 'missing links'), now there is an increasing interest in them (see some other articles below).

In general, these chapters demonstrate that although a great deal of progress has been made in the last few decades, a number of issues need to be resolved, from conceptual to methodological ones, and that most hypogean species, whether they are troglomorphic or not, remain poorly known, which has hampered some of the attempts to synthesize information.

\section{Anatomy, physiology and behavior}

The relationships between morphology, physiology and behavior has always been an important component of hypogean fish research, and five articles in this volume represent current research in that tradition. Montgomery et al. (2001), for example, provide an excellent synthesis of theirs and others' research on the mechanosensory lateral line system of the hypogean form of the characid Astyanax fasciatus. They show how their enhanced lateral line capabilities with respect to their sighted relatives allow them to build up a 'picture' of their environment, a process that has been called active hydrodynamic imaging.

Adams \& Johnson (2001) studied the metabolic rate and natural history of Ozark cavefish, Amblyopsis rosae, in Logan Cave, Arkansas, and found that seasonal relationships between mass and oxygen consumption may reflect alterations in environmental conditions (i.e. food availability, ambient dissolved oxygen) and changes in susceptibility to handling stress. They also report that cannibalism may not always be the rule for this amblyopsid species, as previously suggested.

Berti \& Zorn (2001) report their most recent research on the locomotory responses of the cave cyprinid Phreatichthys andruzzii to chemical signals from conspecifics and related species. Contrary to what was previously believed, they found that there was not a positive chemotaxis to the odor of known or unknown conspecifics, but rather a strong negative chemotaxis towards the odor of unfamiliar conspecifics and of individuals belonging to the closely related species Barbus conchonius.

Camassa (2001) studied the responses to light in epigean and hypogean populations of the poeciliid Gambusia affinis from the brackish water basins of the 'Spunnulate' dolinas system of Torre Castiglione, in southeastern Italy. She found that the hypogean individuals showed, on average, scotophilia (photophobia) with little variability in their responses. On the other hand, epigean and spring-dwelling individuals of G. affinis from the same region showed the opposite behavior and with a great variability in their responses when compared with cave-dwelling conspecifics.

Pati (2001) presents the results of his latest experiments on the temporal organization in locomotor activity of the hypogean loach, Nemacheilus evezardi, and its epigean ancestor. His studies suggest that hypogean fish still possess a functional oscillator underlying their overt circadian rhythm in locomotor activity, although the ecophysiological significance of this proposition is yet to be fully understood.

\section{Ecology and conservation}

In the last decade, there has been an increased interest on the ecology and conservation status of these fishes. Thanks to the use of capture-recapture methods, which allows the gathering of data instead of the mostly casual observations of the past, new testable hypotheses have been presented and more precise information 
has become available. Trajano (2001a), for example, presents an overview on the ecology of hypogean fishes by synthesizing the available ecological data and comparatively analyzing that in an evolutionary context.

Brown \& Johnson (2001) give us the results of their population studies and growth of the Ozark cavefish, Amblyopsis rosae, in Logan Cave National Wildlife Refuge, Arkansas. According to their results, this threatened species, endemic to the Springfield Plateau of the Ozark Highlands in Arkansas, Missouri, and Oklahoma, has a maximum life span of 4-5 years. They found that this fish has an average rate of growth of $0.6 \mathrm{~mm}$ per month, though smaller fish grew faster than larger fish

Noltie \& Wicks (2001), on the other hand, took a look at how hydrogeology has shaped the ecology of Missouri's Ozark cavefish, Amblyopsis rosae, and the southern cavefish, Typhlichthys subterraneus. They explored how the differences in geography, geology, and hydrology in the habitats of both fish interact in shaping the habitat in which these two species dwell, the resulting ecological constraints that the fishes face, how their ecologies and populations reflect these constraints, and how conservation and management efforts may need to be tailored to best compliment the unique challenges that each species presents.

Trajano (2001b) studied the habitat and population biology of the armored cave catfish, Ancistrus cryptophthalmus, from Central Brazil and found this species to be a typical bottom-dweller with a strong preference for rocky substrates in fast-flowing stream sectors, while having relatively high population densities when compared to other cavefishes, conservatively estimated at 20000 individuals.

Proudlove (2001) synthesized the conservation status of hypogean fishes and found that these fishes are susceptible to five main threats: habitat degradation, hydrological manipulations, environmental pollution, overexploitation, and introduced exotic species. Because they are endemic to small areas and have small populations, any threat could have serious consequences. Some species are receiving conservation attention; however, most receive none.

Kuhajda \& Mayden (2001) discuss the status of the federally endangered Alabama cavefish, Speoplatyrhinus poulsoni, in caves of Alabama. They found that its population is relatively stable, but recommend continuous monitoring. They also observed a single specimen of Typhlichthys subterraneus in Key Cave, which falsifies the previous assumption that these two species were allopatric.
Three papers of the series 'Threatened fish of the world' round up this section with narratives on Caecobarbus geertsii (Proudlove \& Romero 2001), Ophisternon infernale (Medina-González et al. 2001), and Ogilbia pearsei (Proudlove et al. 2001).

\section{Genetics and evolution}

This section contains five articles that examine genetic and evolutionary issues from different perspectives. Molecular techniques are helping tremendously to understand the true evolutionary nature of many hypogean populations while underlying the fact that drastic phenotypic differences between epigean and hypogean populations may result from very little genetic modifications. Borowsky \& Mertz (2001) for example, report on the genetic differentiation among populations of the balitorid cave fish, Schistura oedipus, from Thailand by using DNA analysis. They found that the five populations they studied were little differentiated and that $S$. oedipus appears to be more closely related to $S$. poculi than to $S$. reidi, a proposed sister taxon.

Espinasa \& Borowsky (2001) used RAPD markers to explore the origins and relationships of cave populations of the blind Mexican tetra, Astyanax fasciatus, in the Sierra de El Abra. Their restalts indicate that all cave populations are more closely related to one another than they are to the surface populations. This suggests that present day cave populations derived from a common ancestral stock, most likely due to a single colonization event, or alternatively, that strong gene flow among cave populations has occurred, raising precaution against considering each cave population as independent.

Poulson (2001a) studied the morphological and physiological correlates of evolutionary reduction of metabolic rate among amblyopsid cave fishes. He reports multiple correlates of reduction in metabolic rate during evolutionary adaptation to caves in the fish family Amblyopsidae. He found that no trait that could contribute to a lowered metabolic rate is in the same rank order as metabolic rate, though collectively the reductions were in the same order as metabolic rates. He explains that this was as expected with convergent evolution of complex traits.

Wilkens (2001) describes the convergent adaptations to cave life in the pimelodid Rhamdia laticauda catfish group from Central America. This species gave rise to a number of cave species. Comparison between two 
of them, $R$. zongolicensis and $R$. reddelli, reveals an intermediate state of reduction of the biologically functionless eyes, melanin pigmentation, and scotophilia. Given that the surface species is perfectly adapted to life in darkness, only a few constructive adaptations are developed in the cave species. For survival under conditions of low food supply in the caves, the barbels are elongated to improve the senses of taste and touch, and more fat can be deposited in the cave fish's tissue. Due to convergent evolution, the two cave species are morphologically much alike and show only minor diagnostic meristic differences. From geologic data he concluded that the two cave species started their troglobitic evolution at the end of the Pleistocene.

Finally, Parzefall (2001) reviews morphological and behavioral changes in the cave molly, Poecilia mexicana, from Tabasco, Mexico, which successfully colonized a sulfur cave. The eye size, melanin pigmentation and scale tuberances, as well as aggressive and schooling behavior, are reduced in the cave fish to a certain degree. Besides these regressive characters, he found some constructive ones such as an enlarged genital region in the female and an increased number of taste buds on the upper side of the head in both sexes. Nearly all the characters he studied form a genetically based gradient from the beginning to the end of the cave, which seems to be the result of gene flow from the outside to the inner part of the cave. He also reports on a special behavioral adaptation found among females which prefer bigger males during courtship. In darkness, only the cave females show this preference.

\section{Special cases}

Some of the contributing authors concentrated their efforts in taking a holistic view of some unusual populations. For example Burr et al. (2001) studied the cavernicolous sculpins of the Cottus carolinae species group in Perry County, Missouri. They found that this fish occupies pools and riffles of cave streams, occurring on a variety of substrates, from sediment to breakdown. A number of phenotypic characteristics separate the epigean from the hypogean form and these results are interpreted as being representative of losses associated with long-term cave habitation.

Humphreys (2001) summarized the current information on the eleotrid cavefish Milyering a veritas from the arid tropics of northwestern Australia which include some of his own biogeographic studies. He found allozyme frequencies and distributions indicating significant population sub-structuring on the Cape Range peninsula. Further, he suggests that the vicariant events may have been associated with a series of eustatic low sea levels.

Hendrickson et al. (2001) present an overview of recent explorations in search of ictalurid Mexican blindcats, of the genus Prietella. Based on the data gathered from their visits to more than 50 sites they recommend threatened status for Prietella phreatophila. They located a new site for $P$. lundbergi and think that this species should probably be considered endangered.

Espinasa et al. (2001) describe a new blind cave fish population of genus Astyanax in Granadas Cave, in the Balsas drainage, southern México. They suggest that this new blind morph represents an independent colonization and convergent adaptation to the cave environment by this fish species. Individuals of this population display variability of their troglomorphic features, including asymmetrical degeneration of the eyes. They found that loss of pigmentation and eye reduction, although sometimes correlated, were not always linked with reduced eyes found on pigmented fish and unpigmented fish with normal eyes. Some individuals had reduced lens size or an absence of lens altogether and the retina was highly modified with photoreceptors sometimes absent.

Finally, this volume closes with an article by Poulson (2001b) in which he tries to show the importance of a broad comparative approach on morphology, physiology, behavior, life histories, and ecology that, when coupled with similar studies on deep-sea fishes, provides some interesting insights on the evolutionary history of both types of fishes, and suggests future lines of research.

As it usually happens in science, this volume provides some answers, but many more questions have yet to be elucidated. That is what makes our job so much fun.

\section{Acknowledgements}

Kelly M. Paulson, Jon Beland, and Kathryn Benz helped me proofreading many of the articles and getting in touch with some of the authors for further clarification. Ann Esson helped to prepare some of the final figures and provided extraordinary logistical support. Finally, I am deeply thankful to Eugene K. Balon who provided editorial assistance and advice in the always complicated task of putting together a volume like this. 


\section{References cited}

Adams, G.L. \& J.E. Johnson. 2001. Metabolic rate and natura history of Ozark cavefish, Amblyopsis rosae, in Logan Cave, Arkansas. Env. Biol. Fish. 62: 97-105.

Balon, E.K. 1981. Saltatory processes and altricial to precocia forms in the ontogeny of fishes. Amer. Zool. 21: 573-596.

Balon, E.K. 1989. The epigenetic mechanisms of bifurcation and alternative life-history styles. pp. 467-501. In: M.N. Bru ton (ed.) Alternative Life-History Styles of Animals, Perspectives in Vertebrate Science 6, Kluwer Academic Publishers, Dordrecht.

Berti, R. \& L. Zorn. 2001. Locomotory responses of the cave cyprinid Phreatichthys andruzzii to chemical signals from conspecifics and related species: new findings. Env. Biol. Fish. 62: $107-114$.

Borowsky, R.B. \& L. Mertz. 2001. Genetic differentiation among populations of the cave fish, Schistura oedipus (Cypriniformes: Balitoridae). Env. Biol. Fish. 62: 225-231.

Brown, J.Z. \& J.J. Johnson. 2001. Population biology and growth of Ozark cavefish in Logan Cave National Wildlife Refuge, Arkansas. Env. Biol. Fish. 62: 161-169.

Burr, B.M., G.L. Adams, J.K., Krejca, R.J. Paul \& M.L. Warren, Jr. 2001. Troglomorphic sculpins of the Cottus carolinae species group in Perry County, Missouri: distribution, external morphology, and conservation status. Env. Biol. Fish. 62: 279-296.

Camassa, M.M. 2001. Responses to light in epigean and hypogean populations of Gambusia affinis (Cyprinodontiformes: Pocciliidae). Env. Biol. Fish. 62: 115-118.

Espinasa, L. \& R.B. Borowsky. 2001. Origins and relationship of cave populations of the blind Mexican tetra, Astyanax fasciatus, in the Sierra de El Abra. Env. Biol. Fish. 62: 233-237.

Espinasa, L., P. Rivas-Manzano \& H. Espinosa Pérez. 2001. A new blind cave fish population of genus Astyanax: geography, morphology and behavior. Env. Biol. Fish. 62: 339-344.

Hendrickson, D.A., J.K. Krejca \& J.M. Rodríguez Martinez. 2001. Mexican blindcats genus Prietella (Siluriformes: Ictaluridae): an overview of recent explorations. Env. Biol. Fish. 62: 315-337.

Humphreys, W.F. 2000. Background and glossary. pp. 3-14. In: H. Wilkens, D.C. Culver \& W.F. Humphreys (ed.) Subterranean ecosystems. Elsevier, Amsterdam.

Humphreys, W.F. 2001. Milyeringa veritas (Eleotridae) a remarkably versatile cave fish from the arid tropics of northwestern Australia. Env. Biol. Fish. 62: 297-313.

Kuhajda, B.R. \& R.L. Mayden. 2001. Status of the feder ally endangered Alabama cavefish, Speoplatyrhinus poutson (Amblyopsidae), in Key Cave and surrounding caves, Alabama. Env. Biol. Fish. 62: 215-222

Medina-González, R., G. Proudlove, L. Chumba-Segura \& T. Iliffe. 2001. Threatened fishes of the world: Ophisternon infernale (Hubbs, 1938) (Synbranchidae). Env. Biol. Fish. 62: 170

Montgomery, J.C., S. Coombs \& C.F. Baker. 2001. The mechanosensory lateral line system of the hypogean form of Astyanax fasciatus. Env. Biol. Fish. 62: 87-96.
Noltie, D.B \& C.M. Wicks. 2001. How hydrogeology has shaped the ecology of Missouri's Ozark cavefish, Amblyopsis rosae, and southern cavefish, Typhlichthys subterraneus: insights on the sightless from understanding the underground. Env. Biol. Fish. 62: 171-194.

Parzefall, J. 2001. A review of morphological and behavioural changes in the cave molly, Poecilia mexicana, from Tabasco, Mexico. Env. Biol. Fish. 62: 263-275.

Pati, A.K. 2001. Temporal organization in locomotor activity of the hypogean loach, Nemacheilus evezardi, and its epigean ancestor. Env. Biol. Fish. 62: 119-129.

Poly, W.J. 2001. Nontroglobitic fishes in Bruffey-Hills Creek Cave, West Virginia, and other caves worldwide. Env. Biol. Fish. 62: 73-83.

Poulson, T.L. 2001a. Morphological and physiological correlates of evolutionary reduction of metabolic rate among amblyopsid cave fishes. Env. Biol. Fish. 62: 239-249.

Poulson, T.L. 2001 b. Adaptations of cave fishes with some comparisons to deep-sea fishes. Env. Biol. Fish. 62: 345-364.

Proudlove, G.S. 2001. The conservation status of hypogean fishes. Env. Biol. Fish. 62: 201-213.

Proudlove, G., R. Medina-González, L. Chumba-Segura \& T. Iliffe. 2001. Threatened fishes of the world: Ogilbia pearsei (Hubbs, 1938) (Bythitidae). Env, Biol. Fish. 62: 214

Proudlove, G.S. \& A. Romero. 2001. Threatened fishes of the world: Caecobarbus geertsi Boulenger, 1921 (Cyprinidae). Env. Biol. Fish. 62: 238.

Romero, A. 2001. Scientists prefer them blind: the history of hypogean fish research. Env. Biol. Fish. 62: 43-71.

Romero, A. \& K.M. Paulson. 2001. It's a wonderful hypogean life: a guide to the troglomorphic fishes of the world. Env. Biol Fish. 62: 13-41.

Thinès, G. 1969. L'evolution regressive des poissons cảvernicoles et abyssaux. Masson et Cie, Paris. 394 pp.

Trajano, E. 200 lb. Habitat and population data of troglobitic armoured cave catfishes, Ancistrus cryptophthalmus Reis, 1987, from central Brazil (Siluriformes: Loricariidae). Env Biol. Fish. 62: 195-200.

Trajano, E. 2001a. Ecology of subterranean fishes: an overview. Env. Biol. Fish. 62: 133-160.

Wilkens, H. 2001. Convergent adaptations to cave life in the Rhamdia laticauda catfish group (Pimelodidae, Teleostei). Env. Biol. Fish. 62: 251-261.

\section{Appendix. Glossary of terms frequently used in this special volume and that are unique to biospeleological studies. For a more expansive list of terms, see Humphreys (2000)}

Anchi(h)aline: Aquatic habitats with a restricted exposure to open air, with one or more connections to the sea, that is influenced by both the marine and terrestrial ecosystems with which they interface. They are common in volcanic or limestone bedrock. Some examples of anchialine fishes are species of the 
genus Lucifuga in Cuba and the Bahamas as well as Ogilbia galapagosensis from the Galápagos Islands, Milyeringa veritas and Ophisternon candidum from northwestern Australia.

Cave: A hollow place in the earth. For cavers any natural hole, vertical, horizontal, or a combination of both which can be penetrated by a human being is a cave.

Cavernicole, cavernicolous: Any organism living in caves.

Cenote: A flooded, natural depression carved out of friable limestone with collapsed ceiling. The word cenote is Spanish but derived from the Mayan word tzonot which is somewhat loosely used in the Yucatán Peninsula of Mexico, to refer to various types of bodies of waters contained in cavities in the limestone which makes up the flat plain that constitutes that peninsula.

Crenobionts: Organisms normally found in springs and spring brooks.

Epigean: The surface environment as opposed to the hypogean one. It also applies to organisms living there.

Hypogean: The subsurface or subterranean environment as opposed to the epigean one. It also applies to organisms living there.

Karst: Soluble-rock landscape product of a combination of high rock solubility and well-developed secondary solubility. They have sinking streams, caves, enclosed depressions, flute rock outcrops, and large springs. The word derived from the name Karst (today Kars) used until early this century to describe a region in the Italian-Slovenian border with that name.

Phreatic: Underground source of water.

Scotophilia: Tendency to stay away from light exhibited by many hypogean organisms including blind ones (they use other sensory systems to detect light).

Spel(a)ean: Pertaining to cave.

Speleogenesis: The origin and development of caves.
Stygobiont: Organisms that inhabit groundwaters.

Stygobite: Hypogean organisms that show some sort of specialization to the underground environment. Adaptations may include, but are not restricted to, eye reduction, depigmentation, reduction of scale number, hyperdevelopment of some sensory organs, reduction in metabolic rates, reduction or disappearance of circadian rhythms, reduction in fecundity, increased egg size, increased life span, increased starvation resistance, reduction or disappearance of certain behaviors such as aggressiveness, schooling, and response to alarm substances. They are obligatory organisms to that environment. This term is similar in meaning to troglobite and to the precocial life-history style derived from the altricial style of the epigean ancestor (e.g., Balon 1981, 1989)

Stygofauna: Fauna inhabiting the underground water environment.

Stygophile: An organism that frequently visits and exploits hypogean resources. A fish example is the Chinese cyprinid Varicorhinus (Scaphestes) macrolepis which hibernates for about six months in the comparatively warm and stable cave waters (Zhang 1986). Another is Chologaster agassizii which occurs in springs and caves (but almost always near the surface). Lives underground but emerges above ground in springs (this term is similar in meaning to troglophile).

Stygomorphic: Organism that displays convergent phenotypic (morphological, physiological, and behavioral) characteristics of stygobites. This term is similar in meaning to troglomorphic.

Stygoxenes: Organisms that can be found accidentally in the hypogean environment. This term is similar in meaning to trogloxene.

Troglobite: (see stygobite).

Troglomorphic: (see stygomorphic)

Troglophile: (see stygophile).

Trogloxene: (see stygoxene). 